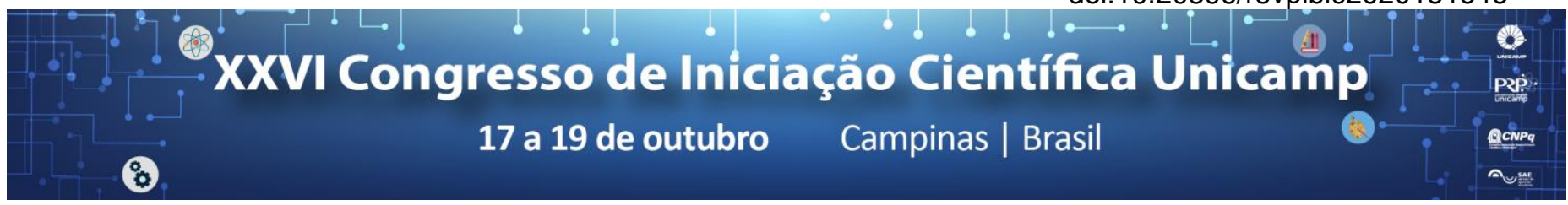

\title{
Análise e Diagnóstico de Falha em Motor Brushless DC
}

\section{Victor S. Tanaka*, Mateus Giesbrecht}

\section{Resumo}

Essa pesquisa tem os objetivos de estudar, analisar e diagnosticar falha em motor BLDC (Brushless DC) através de duas formas. A primeira é calcular alguns parâmetros do circuito equivalente da máquina, através de ensaios e medições de tensões e correntes, e classificar a falha através da variação dos parâmetros. A segunda é coletar sinais de vibrações que serão causados pela falta de uma das fases de alimentação, calcular sua resposta em frequência através de alguns modelos matemáticos, e classificar a falha com uma rede neural e um classificador utlizando Lógica Fuzzy.

\section{Palavras-chave:}

Falhas, Redes Neurais, Parâmetros da máquina

\section{Introdução}

Motores Brushless DC são motores de corrente contínua, que como o nome diz, não possuem escovas. Os motores BLDC tiveram seu uso crescente nos últimos anos devido à alta eficiência, controle preciso de torque e velocidade e baixo custo de manutenção. O estudo e diagnóstico de falhas em motores acompanhou esse crescimento devido à constante preocupação com a segurança em linhas de produção e com 0 fator econômico. Deste modo, as técnicas aplicadas são o estudo do espectro de frequência da corrente e a implementação de redes neurais para processar os dados obtidos. Desta forma, neste projeto, se busca estudar um tipo de falha em um motor BLDC através de duas abordagens: uma baseada em modelo, e outra baseada na comparação dos espectros em frequência das vibrações da máquina.

\section{Resultados e Discussão}

Neste estudo, foi utilizado o modelo caixa cinza ARX obtido através das equações a diferenças obtidas através do equacionamento apresentado para a dinâmica do motor e para o circuito elétrico equivalente. Além disso, foi utilizado o Método dos mínimos quadrados para determinar os parâmetros elétricos e mecânicos da máquina a partir de dados coletados em ensaios.

Tabela 1. Resultados dos parâmetros da máquina

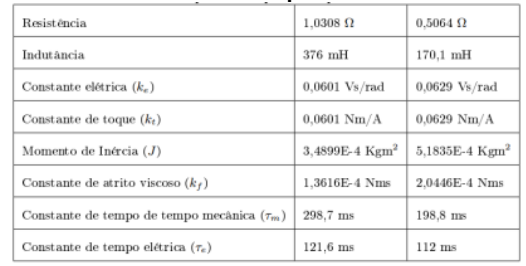

$\mathrm{Na} 2^{\mathrm{a}}$ parte, foi utilizada uma rede neural artificial, programada através do toolbox Neuro-Fuzzy Designer no Matlab.que realizou a função de classificador da falha.

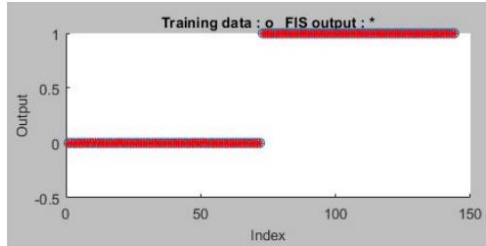

Figura 1. Resultados de saída da rede neural para dados de treinamento para os eixos $X$ e $Y$

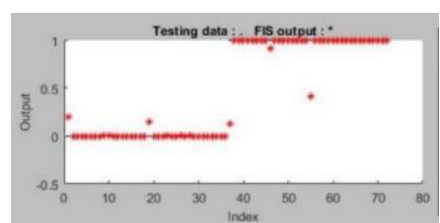

Figura 2. Resultados de saída da rede neural para dados de teste para os eixos $X$ e $Y$

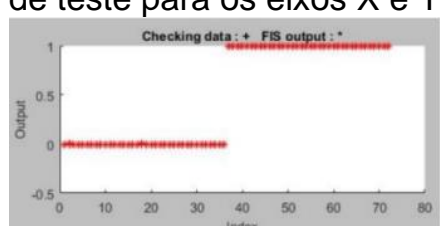

Figura 3. Resultados de saída da rede neural para dados de validação para os eixos $X$ e $Y$

\section{Conclusões}

No caso da abordagem baseada em modelo, nota-se que, no caso com falha, os parâmetros estimados de resistência e indutância apresentaram redução de aproximadamente $50 \%$ em relação aos valores calculados com os dados sem falha. Isso é esperado uma vez que a falha está relacionada à retirada de um dos circuitos elétricos da máquina. Nota-se também da tabela que as constantes elétrica e de torque não apresentaram mudanças significativas. Isso é esperado pois elas dependem exclusivamente de características construtivas da máquina, que não são afetadas pela falha introduzida

No caso da rede neural, é possível observar que, utilizando os dados dos eixos $X$ e $Y$, foi possível classificar a falha de forma satisfatória, com reconhecimento claro da falha pela rede neural.

\section{Agradecimentos}

Agradecimentos à FAPESP e a Faculdade de Engenharia Elétrica e de Computação (FEEC) da Unicamp.

1Da Silva, Rodrigo; "IDENTIFICAÇÃO DE PARÂMETROS E PROJETO DO SISTEMA DE CONTROLE DE VELOCIDADE DE MOTORES DE CORRENTE CONTÍNUA SEM ESCOVAS BLDC”, 2017.

2Aguirre, "Introdução à identificação de sistemas", 2004.

${ }^{3}$ Goode, P. V.; M. Y. Chow; "Using a Neural/Fuzzy System to Extract

Heuristic Knowledge of Incipient Faults in Induction Motors: Part 1 Methodology", 1995. 